\title{
Understanding Online Teacher Best Practices: A Thematic Analysis to Improve Learning
}

Michael Corry, Robert lanacone \& Julie Stella

\begin{abstract}
The purpose of this study was to examine brick-and-mortar and online teacher best practice themes using thematic analysis and a newly developed theory-based analytic process entitled Synthesized Thematic Analysis Criteria (STAC). The STAC was developed to facilitate the meaningful thematic analysis of research based best practices of K-12 education delivery options. In the study, data for the thematic analysis consisted of published research about best practices in both brick-and-mortar and online education. The use of both brick-and-mortar as well as online teacher best practices provided an opportunity to identify commonalities among these modes of delivery. Based on these commonalities, the thematic analysis detected emergent themes, which could be used as a foundation upon which online teachers might build specialized practice. As well, research-validated teacher best practice themes generated from this study may be considered a starting point for defining teacher best practices in online education and for their development. Emergent themes were discussed in the context of the data and the environment of online education. The STAC analytic process provides a foundation for analysis and may be used by researchers for other thematic analyses in the future.
\end{abstract}

This is the author's manuscript of the article published in the final edited form as:

Corry, M., lanacone, R., \& Stella, J. (2014). Understanding Online Teacher Best Practices: A Thematic Analysis to Improve Learning. E-Learning and Digital Media, 11(6), 593-607. 


\section{Introduction}

The use of teacher best practices to enhance and specialize a teacher's pedagogical strategy has long been encouraged (Healy \& Welchert, 1990; Dawson et al, 2013). Indeed, for over a century and continuing into today, traditional brick-and-mortar elementary and secondary schools have reacted to our changing society by re-defining and adapting teacher best practices in an attempt to keep pace with societal needs and challenges (Feiman-Nemser, 1996; DiPietro, 2010). The adaptation is particularly evident when considering how education needs have changed from the previous century to today's highly technical online information age. A similar evolution is at work in online education, which is relatively new, filling an unmet need, and growing at a rapid pace (Corry \& Stella, 2012). As this online evolution has progressed, it has become increasingly clear that while many current education policies can be implemented similarly in both online education and traditional brick-and-mortar education, teacher best practices are somewhat more difficult to put into action universally because the modes of delivery are fundamentally different (Rice, 2006; Tucker, 2007; DiPietro et al, 2008; Black et al, 2009; Cavanaugh et al, 2009; Oliver et al, 2009). Therefore, the prescribed best practices for teaching online might differ significantly from best practices for teaching in brick-and-mortar education. However, some similarities in best practice approaches likely remain. Therefore, teacher best practice recommendations from research studies of brick-and-mortar education could be considered as a starting point when developing teacher best practices for online education because they are likely to reflect an advantage based on the time for research to be conducted, controlled experimentation, informed experience, and developmental maturity. In addition, research involving teacher best practices from online education, may add value as well.

\section{Methodology}

Many studies comparing and contrasting brick-and-mortar and online education have been undertaken in the past, and they are a source of continued interest for researchers. For example, brick-and-mortar and online education have been juxtaposed in previous research studies to derive a variety of comparisons to determine which, if either, produce higher student outcomes (Allen et al, 2002; Bernard et al, 2004; Sapp \& Simon, 2005; O'Dwyer et al, 2007; O'Neal et al, 2007; Means et al, 2009; SivinKachala \& Bialo, 2009; Edwards et al, 2011). Considering these two education delivery modes in the context of one another seems a source of continued interest as can be seen in more current studies (Battaglino et al, 2012; Boston et al, 2012). However, some researchers believe the field of online education has moved beyond the need to compare and prove which mode is 'best' (Allen et al, 2002; Rice, 2006; Bernard et al, 2009; Abrami et al, 2011). Indeed, many newer studies focus on brick-andmortar and online education as complimentary opportunities, such as blended environments, which can add exponential value for all learners. Brick-and-mortar and online education continue to find further complimentary contexts, such as the exchange of research knowledge construction (Dawson et al, 2013), combined trend-analysis for scalability planning (Glick, 2011; Watson et al, 2012), the analysis of social discourse within brick-and-mortar and online education delivery systems (O'Brien et al, 2011), and this thematic analysis of teacher best practices.

The current study was undertaken to derive underlying socially constructed themes from best practices in both brick-and-mortar and online education in K-12 settings. Analyzing these modes of education in the context of one another is a source of continued interest for researchers, and this study was undertaken with a similar interest. The themes derived from the analysis may provide a foundation for the construction of online teacher best practices because those that begin with a valid foundational 
support are more likely to be successful (Vesely, 2011; Spencer et al, 2012). Implementing a meaningful thematic analysis of this kind can be challenging for many reasons. To manage these issues, an analysis of the literature was conducted to validate emergent themes. In addition, delimiting a corpus for such an analysis can also be tremendously difficult; therefore, a theory-based analytic process, Synthesized Thematic Analysis Criteria (STAC), was developed to overcome this issue. STAC operates as a series of sieves to minimize intervention from inapplicable texts and allow researchers to define the study.

Thematic analysis is a variant of discourse analysis. Thematic analysis seeks to understand the social foundation of a related group of texts or dialog called a corpus. To date, many discourse analysis studies of online education have been undertaken, which derive themes of culture, teacher identity, and education as social constructions, (Clarke, 2009; Lam, 2009; Buckingham-Shum \& Ferguson, 2012). Similarly, analyzing a delimited corpus of brick-and-mortar and online education teacher best practices may allow themes to emerge from the texts (Fairclough, 2003; Fulcher, 2012), which could serve as a starting point to inform further development of online teacher best practices and add value to both educational modes. Teacher best practices are widely seen as 'what works' in education, but they exist in many forms from personal advice among teachers to rigorous research studies published in peerreviewed academic journals. Of these possible sources, a corpus of peer-reviewed case studies, which highlight best practices across all education modes is an excellent resource for analysis. However, teacher best practice case studies vary widely in research method, level of abstraction, desired outcome from the study, context, stakeholder focus, and date published, so delimiting this corpus can be challenging.

To manage these difficulties, this analysis relied on a case study selection process. The first step of the selection process yielded approximately 2600 articles, which were selected from two educational databases of peer-reviewed academic articles using best practices, instructional practices, and education as search criteria. Some of the articles were then discarded upon noting inapplicable words in the title of the article or if the study did not examine $\mathrm{K}-12$ populations. The remaining 59 articles were then reviewed using the STAC analytic process as follows:

1. The case studies were narrowed by research method using an existing definition of best practices from the US Department of Health and Human Services (HHS).

2. The remaining case studies were further narrowed using criteria from the theory-based Best Practice Research Theory Methodology.

3. The Education Benchmarking Methodology parameters were applied last in order to select a set of similar peer-reviewed case studies.

Used together, these techniques of the STAC analytic process yielded a selection of case studies from which a meaningful analysis of teacher best practices was derived. To view teacher best practices as complimentary, an equal number of the most current brick-and mortar and online education case studies were selected. To increase validity, data triangulation (Guion et al, 2012) was used to select a sample of three cases from each brick-and-mortar and online education for analysis.

\section{Research-validated and Field-tested Best Practices}

Identifying best practices in a usable way for continuous improvement of outcomes has been difficult in many fields besides education. Indeed, in 2012 , the issue of variations in the way best practices were derived among internal case studies was recognized as problematic by the US Department of Health and Human Services (HHS) because the differences often resulted in misunderstandings among projects. To 
resolve this difficulty, the HHS worked with consultants to derive their own nomenclature for best practices. They examined sets of best practices at a granular level and identified three types of best practices: research-validated, field-tested, and promising practices.

\section{Research-validated best practices}

A program, activity or strategy that has the highest degree of proven effectiveness supported by objective and comprehensive research and evaluation.

\section{Field-tested best practices}

A program, activity or strategy that has been shown to work effectively and produce successful outcomes and is supported to some degree by subjective and objective data sources.

\section{Promising practices}

A program, activity or strategy that has worked within one organization and shows promise during its early stages for becoming a best practice with long term sustainable impact. A promising practice must have some objective basis for claiming effectiveness and must have the potential for replication among other organizations (US Department of Health and Human Services, 2012, p. 4).

By these definitions, many best practices in education are of the promising variety, but comparatively few are field-tested or research-validated. Promising practices are often created and intended for use in specific districts or schools in order to solve specific problems. Their strengths are many, but their weaknesses lie in their dependence on specific context, actors, and rhetorical situations. By contrast, field-tested and research-validated best practices, with their more abstract tendencies, may be more widely applicable to a variety of schools and classrooms (Peters \& Heron, 1993; Spencer et al, 2012). The HHS classification criteria describe field-tested best practices as 'effective in more than one context' ( $p$. 4) and research-validated best practices as those that have been endorsed after 'comprehensive and objective evaluation by an external, qualified source' (p. 4). Thus, in education case studies, research projects that evaluated teachers in more than one classroom or school may be deemed field-tested, and research studies that are reviewed by a panel of peers may be considered research-validated. Using these definitions, only the HHS defined 'field-tested' and 'research-validated' studies were included in this analysis, so that broad utility could be distilled from the analysis.

\section{Best Practices Research Methodology}

Best Practices Research (BPR) is a process-improvement approach applied in management and academic environments. Best Practices Research is based on the idea that implementing an already proven practice, or a practice derived from a proven practice, is better than developing something entirely new. Though a logical idea, BPR proved difficult to implement because of varying ideas about techniques used to define best practices. Indeed many scholars found '... literature on best practices research [to be] confusing, terminology incoherent, fragmented, and in many ways inconsistent. There is no consensus on what BPR actually is and how it should be properly conducted' (Vesely, 2011, p. 99). Thus, BPR methodology evolved in response to difficulties with BPR. BPR methodology uses a theoretical foundation for identifying comparable practices. BPR methodology can be grounded in either economic theory (specifically, production theory) (Bretschnieder et al, 2005) or social mechanisms (Elster, 1998; Hedstrom and Sweberg, 1998), which are called upon when identifying candidate practices. After the 
candidates are identified, BPR methodology requires a 'condition of comparability' for determining whether the practices were validly comparable, and a 'condition of completeness' for determining whether all practices had been considered. BPR methodology seeks to constrain the wide-ranging field of research involving best practices, so that comparisons are meaningful and usable.

In a recent critical review of BPR methodology, Vesely (2011) suggests additional parameters for comparing individual best practices in organizations and institutions. Vesely's recommendations for comparing best practices among institutions are summarized as follows:

- Best practices should identify what is to be achieved and comparisons among best practices should have similar goals.

- Best practices should be abstract enough for transferability among organizations or institutions.

- Best practices should be described in the context in which they work.

- Best practice analyses should also describe what does not work.

- Best practices should be continually updated with future research (Vesely, 2011).

\section{Education Benchmarking Methodology}

Choosing cases to compare in a meaningful thematic analysis rather than examining the entire population of practices remains a critical issue, which may be managed further using Education Benchmarking Methodology. Education Benchmarking Methodology is a strategy of best practice review that resolves the case choice difficulty in BPR by recommending researchers use homogeneity to guide case choice. According to researchers, the most important task of benchmarking is choosing studies that demonstrate success and support a meaningful comparison (Moreland et al, 2000; Nazarko et al, 2009). In an education benchmarking study, successful programs or institutions are selected for examination in order to discover their best practices and use these discoveries to improve performance. Using Education Benchmarking Methodology as guidance, case studies for this analysis were constrained by homogeneity in stakeholder and year published.

\section{Synthesized Thematic Analysis Criteria (STAC)}

Synthesized Thematic Analysis Criteria (STAC) is based on the combined use of HHS Research Methods, Best Practices Research Methodology (BPR) and Educational Benchmarking Methodology. Table I presents a summary of the STAC analytic process. Best practice case studies selected using these parameters should be similar, which provides the theoretically based selection criteria required to uncover and validate emergent themes in the texts. These criteria provide a foundation for analysis and may be used for any best practice thematic analysis - from best practices for managing bullying in schools to best practices for preparing women and minority students for education and careers in STEM fields. The STAC process also provides a way to analyze a large selection of best practice research analyses and derive a foundational set of best practices upon which a teacher may build a specialized practice.

Using the methods outlined in Table I for case study selection, a thematic analysis of best practice case studies was conducted to derive emergent themes in this study. The selected sample case studies reflect the following researcher-defined criteria: (a) they produced outcomes that contribute to teaching practice, (b) they were conducted in the context of elementary and secondary schools, (c) they produced outcomes for the teacher as the defined stakeholder, and (d) they were conducted within the 
past five years. In addition, the case studies reflect the following process-defined criteria: (e) the resulting best practices are field-tested or research-validated, and ( $f$ ) they are studied at a level of abstraction for transferability among organizations or institutions. The emergent themes may provide insight for teachers hoping to import best practices from brick-and-mortar education (DiPietro, 2010) or build upon proven, research-based best practices for their own personalized practice. In order to provide context for the reader, the selected case studies are summarized first, and the analysis follows. (Table 1).

\section{Definition of Brick-and-Mortar and Online Education}

For the purposes of this analysis, 'brick-and-mortar' education is defined as an elementary or secondary school with a physical presence, where face-to-face delivery is reported as the primary mode of instruction in the selected case studies. Online education is defined as an elementary or secondary school where courses are delivered online or in a hybrid environment as reported as the primary mode of instruction in the selected case studies. Both education modes serve primarily students in kindergarten through to grade 12; however, both may offer credit recovery classes. Schools offering credit recovery classes are often noted as K-12+. Students in these brick-and-mortar and online education are usually mandated by law to attend school until they are 16 years of age. In some countries, this is called 'compulsory' school.

\section{Brick-and-Mortar Best Practice Case Study Summaries}

Three sample case studies examining brick-and-mortar education best practices were selected using the theory-based STAC analytic process. The case studies are summarized to provide a context for the research of each study.

\section{Brick-and-Mortar Best Practices: case 1}

In this case study, Wilcox and Angelis (2011) used a multiple case methodology in a research validated examination of the complexity of the twenty-first-century school. In the context of school reform, the researchers noted the ethical, moral, and economic reasons to improve schools for all students. With that goal in mind, they designed their research study to identify a set of best practices followed by highperforming schools, so all schools might adopt these successful strategies. The study ranked New York state schools by outcomes to determine the most successful schools. Then, they examined more deeply the better schools at the district, school, and classroom level to determine what made them successful.

Throughout the study, the researchers noted, 'the most successful schools in this study have found a way to adapt and thrive within chaotic and complex environments. They manage to strike a balance between structuring their activity to meet changing requirements coming from outside their districts and providing opportunities for growth and change within' (p. 150). The researchers used chaos and complexity theories instead of other community or group-based theories because schools are affected by circumstances beyond their control, and chaos theory is adept as describing such systems (Gleick, 1987). The researchers collected data from selected schools by interview, and isolated the following summarized themes:

- High-performing schools use rigorous curriculum and have high expectations of all their students. 
- The teachers are free to create innovative instructional programs because they are trusted to focus on strategic goals of the district or school.

- The school maintains transparent communications and recognizes a dependence on all actors parents, students, etc.

- The school used a variety of evidence to make strategic decisions (not just state test scores).

Through face-to-face interviews with administrators and teachers, the researchers compiled best practices pertaining to both groups for managing the complexity of the changing twenty-first century school. The study outcome is a list of teacher and administrator best practices. The research method used in the study is replicable and could be used in other studies.

\section{Brick-and-Mortar Best Practices: case 2}

In this field-tested teacher best practice case study, researchers from The Rennie Center for Education Research \& Policy (2010) present field-tested teacher best practices from a successful school turnaround effort in Boston, MA, USA. Excel High School in Boston was a recently converted small high school in the Boston public school system. It was housed in the top floor of a larger, three-story building, which was previously one school. Over a period of three years, administrators worked to transform the school outcomes using the best practices summarized below:

- Create a school mission statement.

- Set high expectations for instruction.

- Empower teachers through trust allowing innovation to thrive.

- Hold students accountable for high academic and behavioral expectations.

- Prepare all students for college.

- Support students.

The mission of Excel High School is to foster academic achievement and creative expression. Excel High School seeks to cultivate well-rounded students who are prepared for success in college and careers, and to be productive members of a culturally diverse society'. In this case study about school turnaround, the administration, teachers, students, and parents of students implement the mission statement by making significant changes to the operation of the school. As part of the turnaround strategy, teachers were evaluated and offered professional development opportunities to strengthen their effectiveness. Communication and accountability throughout the school was increased, and a culture of continual innovation and change was adopted. Improvements in school safety, outcomes, and attitudes were realized quickly, and the school soon became a 'school of choice' in the Boston school district.

Brick-and-Mortar Best Practices: case 3

This research-validated study by Suarez-Ortega et al (2012) explored teacher best practices from many points of view. The study examined Spanish schools using the Delphi process, which first identifies content experts, then surveys or interviews them to collect data. This study was unique in that the researchers interviewed specialists in the education field, regional council advisors, teacher resource center administrators, general administrators, teachers, and parents of students. Results were distributed across administrators and teachers. According to the findings of the study, a school using best practices should maintain or develop attributes in the following summary: 
- A committed teaching staff that is autonomous, motivated, empathetic, optimistic, and has the capacity to commit themselves and take on responsibilities

- A stable leadership team in the school capable of coordinating, innovating, achieving consensus, and being dynamic

- School participation in innovation and improvement projects

- Family participation in school life

- Coordination among teachers

- Good student-teacher relationships in an appropriate atmosphere

- Teach principles of equity, tolerance, and social justice

The study was conducted in the context of intercultural education, which is increasingly applicable to our global society. In addition, the researchers acknowledge contextual variation as a hindrance to applying best practices over all contexts. The researchers summarize their study with a suggestion that practitioners be open and positive about change and continuous learning.

\section{Online Education Best Practice Case Study Summaries}

The following sample of online education case studies examining online education best practices was selected using the theory-based STAC analytic process. These case studies are summarized to provide a context for the research of each study. Best practices discovered in research study are listed or summarized as well.

\section{Online Education Best Practices: case 1}

In the study, DiPietro (2010) sought to define a research-validated instructional teaching practice, which combined content, pedagogy, and technology into a series of beliefs, goals, and practices for online learning. The research in this article addresses a need for common best practices among all online teachers.

The qualitative research study samples successful instructors from a Midwest-area virtual school based on the results of student outcomes and teacher evaluations. Open-ended interview questions were asked of the teachers, and the results were tabulated and assessed using the constructivist perspective in which knowledge is generated through experience and interaction with the world.

The study was undertaken to explore the perceptions of online teachers about their role as an educator and how they fulfill the role through practices, which produce the best outcomes for students. According to the study, instructional best practices recommended by the teachers are:

- Connecting with students

- Establishing a fluid practice

- Engaging students with the content

- Managing the course

- Supporting student success

The findings of the article are framed to emphasize the relationship between beliefs and practices in online teaching. DiPietro defines beliefs as a comprehensive emergent theme shared among the participants. DiPietro defines a practice as a specific pedagogical or content-oriented undertaking 
implemented in their teaching. The findings of the research study especially underscore the importance of teacher flexibility in a fluid practice, clear communication through engagement and course management, and personalizing learning to ameliorate gaps in understanding.

\section{Online Education Best Practices: case 2}

Black et al (2009) interviewed K-12 online teachers to discover practices they considered successful in their own practice. In the study, the researchers were surprised to discover that K-12 online teachers felt strongly about providing on-site student mentors to work with new online students. The teachers felt mentors added significantly to the success of new online students. In addition to the on-site student mentor finding, additional best practices of online success traits are summarized below:

- Comfortable with technology

- Desire to stay current with changes in technology

- Have the ability to personalize course content to meet the interests of online students.

In the results of a companion research study, DiPietro et al (2008) list research-validated best practices as a benchmark for other teachers. Some notable online teacher best practices from the study are:

- Managing the online classroom appropriately

- Assessing students using various strategies and providing immediate feedback on assignments

- Engaging students with rigorous and interesting content

- Making courses meaningful for students

- Providing support and communication

The researchers also note that classroom management in online settings is a future concern, and that $\mathrm{K}$ 12 online teacher best practices may differ in blended environments where students attend school in both a brick-and-mortar location and online. As with the DiPietro (2010) research, the study results reflect continuing emphasis on relationship development as an online teacher best practice.

\section{Online Education Best Practices: case 3}

Three online high schools were studied in Kerr's (2011a) research-validated multiple-case study - a public school, a charter school, and a consortium of rural schools. In the study, Kerr collected data from various sources about online teachers in the context of the technology they used and the engagement of their students. The collected data was coded and organized by theme. The dominance of technology in online learning enabled the coding of the collected data into generalized pedagogical themes: active learning, constructive learning, intentional learning, authentic learning, and collaborative learning. The online teacher best practices discovered in this study are presented in Kerr's follow-up summary article (2011b) as curriculum and content suggestions to engage learners in online schools. This study offers research-validated best practice benchmarks for teaching online. With benchmarks, best practice recommendations are abstract and schools can use them as guidelines when building their own practice. Notable best practices included:

- Provide many sources of content (video, graphics, and so on) for learners

- Provide timely feedback for students

- Provide opportunities for student choice 
- Provide opportunities for students to manage their own learning program

- Publish rubrics (so learners can understand what is expected)

- Include examples to guide students

- Create authentic learning experiences

- Incorporate activities students find fun to lessen anxiety and encourage engagement

- Use social media to encourage student collaboration and interaction.

The study focused mostly on instructional strategies, but also emphasized engagement and relationships as a key practice for keeping online students working productively. The study explored teacher best practices, student best practices, and school/district best practices in general, but listed only the teacher best practices. The author expressed particular concern for maintaining the rigor of curriculum content, so that the education outcomes meet or exceed state and federal guidelines. In addition, the author suggested using conversational but professional language when contacting students to provide a personalized experience.

\section{Analysis}

In this research analysis, the preceding six teacher best practice case studies were examined, and the emergent themes of teacher flexibility, clear communication, relationship building, and personalized learning surfaced. These themes are both similar and unique to the delivery modes analyzed. The case studies and emergent themes provided insight into successful strategies currently in use for teachers in both brick-and-mortar and online education.

\section{Similar Themes}

Among the emergent themes of this teacher best practices analysis were similar themes shared by brickand-mortar and online education best practices. Indeed, the themes of teacher flexibility and clear communication emerged from both modes of delivery. Although these themes may be applied in different ways in brick-and-mortar and online education, they are both significant in generating successful outcomes for students.

\section{Teacher Flexibility}

Teacher flexibility can be manifest as general flexibility in decision-making and planning, or it can emerge at the classroom level in specific pedagogical strategies. In general, a flexible teacher finds ways to supplement and support learner understanding by reacting to a learner's progress, emotions, and motivation. A flexible teacher can manage the pace of learning and make appropriate modifications to curriculum and pedagogy in order to reach all learners. Wilcox and Angelis (2011) demonstrate supplementing and supporting learner understanding in their best practice recommendation emphasizing innovation and its relationship with flexibility. According to these researchers, implementing a best practice of innovation means, 'teachers are free to create innovative instructional programs because they are trusted to focus on strategic goals of the district or school' (p. 144). This trust encourages '[i]nnovation, risk-taking, and flexibility in developing and revising the schedule, designing new programs, using technologies' (p. 145). Therefore, innovation as a component of flexibility managed with trust and constrained within reasonable parameters of strategic school/district goals can positively affect an entire school. If parameters are developed from field-tested best practices, they may not be seen as limitations, but as guidance. For example, at Excel High School in Boston, 
teachers are required to meet weekly as part of their regular work, but they had complete autonomy and flexibility in how this time was used (Rennie Center for Education Research \& Policy, 2010). Weekly planning meetings are common in brick-and-mortar education, but online teachers are often geographically separated, so they must be even more flexible to implement this best practice. Flexibility emerges as a best practice theme in the Black et al (2009) study of Michigan Virtual School where flexibility was recognized as one of 12 traits named by online teachers as best practices. In a companion study with similar data, DiPietro et al (2008), found that the most successful online teachers are 'flexible with their time' and 'flexible in their use of pedagogical strategies to accommodate varying learning styles' (p. 17, p. 21).

Teacher flexibility was also an emergent theme at the classroom level for researchers Kerr (2011b) and Suarez-Ortega et al (2012). Suarez-Ortega et al suggest teachers use physical space, timetables, and resources in a flexible way as a best practice. Examples from the study are using the entry hall of a school as an exhibition hall or an assembly hall, interrupting classes for current events and one-time unique happenings (such as a live broadcast of a well-known classical concert pianist), and using pages in workbooks flexibly to fit the individual student, rather than used by one student from start to finish. Kerr suggests teachers employ the best practice of offering students choices in assignments and assessments, which demands teacher flexibility. According to Kerr,

Ensuring students have a choice in how they will represent their understanding promotes autonomy and encourages students to take responsibility for their learning. It also encourages the differentiation of learning, as learners are likely to choose activities that are most conducive to their personal learning style. (2011b, p. 29)

As well, Kerr recommends providing opportunities for students to manage their own learning program. Although this requires much flexibility on the part of the teacher, it helps the student gain the important skills of autonomy, self-assessment, and goal setting.

The teacher best practice of flexibility was an emerging theme in nearly all research studies, so it deserves special attention. In these research studies, flexibility was manifest in innovation, which required trust and a system-wide acceptance at all levels. The emergent theme of teacher flexibility may reflect our current culture of innovation where teachers self-identify as innovators. With our varied and changing learner population, it may be common for a teacher to be confounded by programs, assessments, and assignments, which worked beautifully for years, but have become ineffective for no apparent reason. With this knowledge, a teacher can view these programs through the lens of flexibility and perhaps detect problems more quickly and easily.

In brick-and-mortar education, clear communication is manifest in the form of transparency, open dialog, and a climate of trust among teachers, administrators, students, and parents of students. In online education, however, clear communication is manifest additionally in the mutual understanding of communication expectations of teachers, parents, and students. The difference is subtle and nuanced, but notable nonetheless.

Across the teaching modes, administrators, students, parents of students, and other teachers value transparency in decision-making and dialog among the many actors involved in education. Clear communication is vital to providing stability in our ever-changing world because it builds trust, which is the commodity that makes transparency possible. According to Wilcox and Angelis, transparency 'recognizes a dependence on all actors - parents, students, etc.' (2011, p. 146), and this dependence can 
make people feel vulnerable; therefore, trust is essential. Transparent communication also provides an opportunity for actors to share decisions and collaborate, which can empower all.

Empowering a school community through transparent communication can take the form of promoting family participation in school life, encouraging pedagogical coordination among teachers, and creating a safe and positive learning environment (DiPietro, 2010; Rennie Center for Education Research \& Policy, 2010; Suarez-Ortega et al, 2012). In addition to transparency, clear communication can take the form of dialog across all actors in the education system, which creates ownership and belonging by giving everyone a voice (Rennie Center for Education Research \& Policy, 2010). Suarez-Ortega et al (2012) summarize clear communication in the best practice, '[a successful school must have] a stable leadership team in the school capable of coordinating, innovating, achieving consensus, and being dynamic' (p. 8). Clear communication through transparency and dialog makes this best practice possible.

An additional theme of communication expectations was noted in online teacher best practices. Communication expectations are crucial to success in online teaching because non-verbal communication may be absent. Many online courses include audio and video contact among teachers, parents, and students, which provides some non-verbal communication; however, body language, interim work habits, and knowledge of the physical learning environment of the student are not easily accessible to an online teacher. Clear communications expectations can partially bridge this gap by ensuring communication is frequent and mutually managed. According to the research of Black et al (2009) and Kerr (2011b), a teacher in an online course can manage communication expectations from course preparation through assessment. During course preparation, a teacher can publish rubrics of assignments, so learners can understand how their learning will be assessed. A teacher may also provide examples of acceptable assignments to guide learners. Additionally, a teacher may clarify expectations of student conduct in public virtual spaces of the course by publishing guidelines for electronic discussion boards, email, and synchronous class sessions. Assessment through a variety of strategies to accommodate the strengths of different learners, and providing immediate feedback to students are other best practices that reflect the clear communication theme.

\section{Unique Themes}

Two remaining emergent themes of this teacher best practices analysis were unique to online education best practices. These themes are relationship building and personalized learning. Relationship building is crucial to success in online education because it increases student motivation through accountability. Personalized learning allows a teacher to respond to the individual interests and abilities of the students, which may help them remain engaged in learning. Both these themes are reflected in course planning and a wide variety of pedagogical strategies employed by online teachers.

\section{Relationship Building}

Building supportive relationships between teachers and students allows the teacher to shape the online experience through a variety of pedagogical strategies and classroom activities. According to DiPietro (2010), online teachers commit to building supportive relationships with students because they perceive that it increases motivation and success. The vast physical distance that separates teacher and student in online education can confound even the best student; however, frequent communication in a supportive teacher-student relationship may help students know they are not alone in the pursuit of their education, and they have someone to rely on. For example, an online teacher may share information about themselves and/or post frequently to the course website. In addition, an online 
teacher may enhance relationships through shared interest in course content (Black et al, 2009; DiPietro, 2010, Kerr, 2011a). For example, a teacher might provide additional resources about content they can explore together (e.g. the NASA website for an interest in science). Though online education is 'virtual' students must be reminded that their teacher is a real person who will guide them and help them as needed. In secure relationships, an online teacher is better able to manage non-compliance matters such as late assignments or use of inappropriate language on an online discussion board. As well, a teacher may further promote feelings of safety in the shared virtual space while mediating heated online debates among students. An online teacher with positive student relationships can model constructive communication and respect for other opinions while ending the confrontation on a positive note. This is tremendously difficult to do online when confrontations are not happening in real-time, and people often use language they would not normally use in person (Suler, 2004). In these situations, productive teacher-student relationships make it possible to retain a safe virtual classroom even during disagreements. Relationship building is worth the effort for typical students, but it is especially important when students are in crisis. Indeed, DiPietro (2010) relates an incident culled from the research interviews where a student was in danger of hurting himself and posted some text about it on the class discussion board. The teacher was able to help the parents manage the situation, even from a very long distance away. Trusting relationships between teachers and students are especially important in online education where they can build an emotional bridge to lessen the physical distance between teachers and students. A student may work harder and remain a healthy, positive learner in an online class where they are held accountable to someone they know and trust.

An online teacher may also guide students in building supportive relationships with other online students through a variety of pedagogical strategies and classroom activities. Socialization often brings a component of 'fun' to an online course but it is also important for other pedagogical reasons. According to Black et al (2009), 'Communication among students makes a course meaningful for students'. As well, a perceived lack of peer socialization is a major concern for administrators and parents of students (Sivin-Kachala \& Bialo, 2009). To promote student relationships, a teacher may assign team projects and/or use an online discussion board for social and academic activity. An online discussion board is a relationship-enhancing addition to an online course, and there are a variety of ways to use this pedagogical tool to promote student relationships. For example, teachers may consider appointing one student the discussion leader, who summarizes a chapter of text and poses questions for other students to answer. Teachers may also monitor the discussion board for opportunities to encourage continuing discussions among students. DiPietro (2010) suggests using social networking for collaborative activities, so students can build relationships by creating knowledge together, and online games can be another avenue for building relationships. Providing opportunities for online students to build supportive relationships with other online students is a teacher best practice, which may provide a sense of belonging for the student and enhance the educational experience.

The discovery of relationship building as a best practice theme may reflect many social realties; however, it could particularly reflect the globalization of our schools and workplaces. Indeed, collaboration and the ability to maintain productive virtual relationships is a twenty-first century skill, which may serve students well in their future endeavors. In all case studies with an emergent theme of relationship building, researchers found that teachers are most successful when using multiple strategies through multiple activities (Black et al, 2009; DiPietro, 2010; Kerr, 2011b). Students who have experienced online education may be uniquely qualified to adopt this multimodal style to their own online relationships when working with people of different cultures and languages. For example, a student who collaborates with a group in another time zone may choose to record a series of webinars or podcasts in order to share knowledge - a strategy the student learned from his online teacher. 


\section{Personalized Learning}

The discovery of personalized learning as an emergent theme in this teacher best practice analysis may signal that the field of online education is nearing one of its most ambitious goals. For decades, education technology researchers have worked to create adaptive educational software, which personalizes curriculum to the education needs of the user. In combination with this software, the emergent teacher best practice of personalized learning may help develop online education to the next level and realize benefits for all learners. For now, however, personalized learning is primarily manifest in the planning and pedagogical strategies of online education teachers.

Personalized learning through planning allows the teacher to prepare the online learning environment and classroom activities, so they appeal to student interests and abilities. Kerr (2011b) advocates involving the student in planning by helping them set, monitor, and revise goals as the course progresses. In addition, Kerr recommends including students in planning by choosing how they will be assessed when they create a learning unit (presentation, creating a poster, recording a podcast, and so on). Personalized learning is tightly coupled with the emergent teacher best practice of flexibility because an ability to react quickly to changes in student interests and abilities is paramount. Personalized learning through planning was also confirmed in the research study by Black et al, which discovered that one of the most important success characteristics for teachers is, 'the ability to alter course components to reflect the interests and abilities of their students' (2009). Personalized learning through planning can create the course as a unique journey the teacher and student are embarking on together (DiPietro, 2010).

Personalized learning through pedagogical strategies allows the teacher to react to student deficits and mastery of content. Throughout learning, Kerr (2011b), advocates using a conversational style in writing to personalize learning for each student. Similarly, DiPietro (2010), recommends being responsive enough to reword information for the student before they become frustrated. Individualizing the learning is a strong theme from DiPietro's research where 'individualize learning' is a goal categorized under the teacher best practice of 'fluid practice'. The practices in which this goal was manifest are: 'adapting practices to support student; adaptive practice; communicating to individualize instruction; tailoring resources and support for individual student; [and] varying use of practices based on student need' (p. 336). Most importantly, DiPietro recommends keeping the content accessible by monitoring individual student understanding.

Personalized learning is made possible by other emergent teacher best practice themes in this analysis teacher flexibility and managing relationships. In fact, not empowering teachers to alter course content would limit their innovation skills and autonomy, possibly damaging a trust relationship (Black et al, 2009). However, combining teacher flexibility and innovation with adaptive educational software would be a powerful addition to the current education paradigm.

\section{Conclusion}

The STAC analytic process was used to facilitate a thematic analysis of teacher best practices from which the recurring themes of teacher flexibility, clear communication, relationship building, and personalized learning emerged. These best practice themes reveal larger cultural themes such as innovation and globalization while providing a foundation upon which teachers might build their own specialized practice. 
Research-validated teacher best practice themes generated from this study may be considered a starting point when developing teacher best practices. When creating specialized best practices, a teacher of online education can validate the practice against the emergent best practice themes of teacher flexibility, clear communication, relationship building, and personalized learning. If a practice is supported by one or more of these best practice themes, it has a greater likelihood to be successful. For example, a teacher may choose to seek advice from other online teachers about adapting curriculum to help a learner who struggles with ADHD or high-functioning ASD. This action is a teacher best practice because it is supported by the themes teacher flexibility and clear communication. In this way, overall, teacher best practice themes can be considered informed guidelines for creating a successful specialized online teaching practice.

Though this analysis focused on elementary and secondary schools, the STAC analytic process may be employed in other contexts because context is a researcher-defined field. Indeed, early childhood, higher education, and corporate training contexts could be examined as well. Additionally, inputs into the STAC analytic process can be specialized to select best practice case studies for thematic analysis in a number of specialty subtopics, (e.g. instructional design, online education for students with disabilities, online education for gifted and talented students, and online education for students in rural areas).

Best practices in education will likely continue to be influential in shaping our changing educational environment, and will continue to reflect our changing society and the culture of online education. Indeed, this rapidly changing field coupled with shifting demographics will offer a wide range of new research questions and opportunities for years to come. 


\section{Authors}

MICHAEL CORRY is Director of the Center for Advancement of Research in Distance Education (CARDE) at the George Washington University in Washington, DC where he is also an Associate Professor of Educational Technology. Dr Corry's research interests include distance learning and other educational technologies. He has numerous publications and presentations involving his research interests including four books. He holds a PhD from Indiana University. Correspondence: mcorry@gwu.edu

ROBERT IANACONE is Chair of the Advisory Board for The George Washington University Online High School. He holds an EdD from the University of Florida with an emphasis in career/secondary programming for the handicapped. He received his MS with a certificate in learning disabilities and emotional disturbance from the State University of New York at Buffalo. His area of specialization and research interests are in the field of special education, technology integration, and educational technology policy.Correspondence: ianacone@gwu.edu

JULIE STELLA is a researcher at the Center for the Advancement of Research in Distance Education (CARDE) at George Washington University in Washington, DC. She is currently studying education at Johns Hopkins University in the Mind, Brain, and Teaching program. Ms. Stella holds an MA in Professional Writing from Minnesota State University where she teaches Technical Communication, a synchronous online course. She has over 10 years' experience as a software engineer and developer. Correspondence: juliestella@gwu.edu 


\section{Tables}

Table 1. The STAC analytic process

\begin{tabular}{ll}
\hline Guidance & Parameter \\
\hline $\begin{array}{l}\text { Health and Human Services Research } \\
\text { Methods }\end{array}$ & $\begin{array}{l}\text { The research method that defined the best practice } \\
\text { must fit the criteria for research-validated or field- } \\
\text { tested studies }\end{array}$ \\
$\begin{array}{ll}\text { Best Practices Research Methodology } \\
\text { (BPR) }\end{array}$ & $\begin{array}{l}\text { The best practice must reflect a level of abstraction } \\
\text { for transferability among organizations or } \\
\text { institutions }\end{array}$ \\
& $\begin{array}{l}\text { The best practice must reflect defined purpose to } \\
\text { Be achieved (desired outcomes) } \\
\text { The best practice must reflect the defined context } \\
\text { In which the best practices work }\end{array}$ \\
$\begin{array}{ll}\text { Education Benchmarking Methodology } \\
\text { (case-study homogeny) }\end{array}$ & $\begin{array}{l}\text { The best practice must reflect defined } \\
\text { stakeholder focus } \\
\text { The best practice must reflect defined years } \\
\text { published }\end{array}$ \\
\hline
\end{tabular}




\section{References}

Abrami, P., Bernard, R., Bures, E., Boroknovski, E. \& Tamim, R. (2011) Interaction in Distance Education and Online Learning: using evidence and theory to improve practice, Journal of Computing in Higher Education, 23(2), 83-103.

Allen, M., Bourhis, J., Burrell, N. \& Mabry, E. (2002) Comparing Student Satisfaction with Distance Education in Traditional Classrooms in Higher Education: a meta-analysis, American Journal of Distance Education, 16(2), 83-97. http://dx.doi.org/10.1207/S15389286AJDE1602_3

Battaglino, T., Halderman, M. \& Eleanor, L. (2012) The Costs of Online Learning. Partheon Group and Thomas Fordham Institute.

Bernard, R., Abrami, P., Borokhovski, E., et al (2009) A Meta-analysis of Three Types of Interaction Treatments in Distance Education, Review of Educational Research, 79(3), 1243-1289. http://dx.doi.org/10.3102/0034654309333844

Bernard, R., Abrami, P., Lou, Y. \& Borokhovski, E. (2004) A Methodological Morass? How we Can Improve Quantitative Research in Distance Education, Distance Education, 25(2), 175-198. http://dx.doi.org/10.1080/0158791042000262094

Black, E.W., DiPietro, M., Ferdig, R. \& Polling, N. (2009) Developing a Survey to Measure Best Practices of K-12 Online Instructors, Online Journal of Distance Learning Administration, 12(1).

Boston, W., Ice, P. \& Burgess, M. (2012) Assessing Student Retention in Online Learning Environments: a longitudinal study, Online Journal of Distance Learning Administration, 15(2).

Bretschneider, S., Marc-Aurele, F.J. \& Wu, J. (2005) 'Best Practices' Research: a methodological guide for the perplexed, Journal of Public Administration Research \& Theory, 15(2), 307-323. http://dx.doi.org/10.1093/jopart/mui017

Buckingham-Shum, S. \& Ferguson, R. (2012) Social Learning Analytics, Educational Technology and Society, 15(3), 3-26.

Cavanaugh, C., Barbour, M.K. \& Clark, T. (2009) Research and Practice in K-12 Online Learning: a review of open access literature, International Review of Research in Open and Distance Learning, 10(1), 1-22.

Clarke, M. (2009) The Discursive Construction of Interpersonal Relations in an Online Community of Practice, Journal of Pragmatics, 41(11), 2333-2344. http://dx.doi.org/10.1016/j.pragma.2009.04.001

Corry, M. \& Stella, J. (2012) Developing a Framework for Research in Online K-12 Distance Education, Quarterly Review of Online Education, 13(3), 133-151.

Dawson, K., Dana, N.F., Wolkenhauer, R. \& Krell, D. (2013) Identifying the Priorities and Practices of Virtual School Educators using Action Research, American Journal of Distance Education, 27(1), 29-39. http://dx.doi.org/10.1080/08923647.2013.759453

DiPietro, M. (2010) Virtual Schooling Pedagogy: the instructional practices of K-12 virtual school teachers, Journal of Educational Computing Research, 42(3), 327-354. http://dx.doi.org/10.2190/EC.42.3.e

DiPietro, M., Ferdig, R.E., Black, E.W. \& Preston, M. (2008) Best Practices in Teaching K-12 Online: lessons learned from Michigan Virtual School teachers, Journal of Interactive Online Learning, 7(1), 10-35.

Edwards, M., Perry, B. \& Janzen, K. (2011) Making of an Exemplary Online Educator, Distance Education, 31(1), 101-118. http://dx.doi.org/10.1080/01587919.2011.565499

Elster, J. (1998) A Plea for Mechanisms, in P. Hedstrom \& R. Swedberg (Eds) Social Mechanisms: an analytical approach to social theory. Cambridge: Cambridge University Press http://dx.doi.org/10.1017/CBO9780511663901.003 
Fairclough, N. (2003) Analysing Discourse: textual analysis for social research. New York: Routledge.

Feiman-Nemser, S. (1996) Teacher Mentoring: a critical review. Washington, DC: ERIC Clearinghouse on Teaching and Teacher Education.

Fulcher, E. (2012) What is Discourse Analysis? In Cognitive Psychology, http://www.eamonfulcher.com/discourse_analysis.html (accessed June, 2012).

Gleick, J. (1987) Chaos: making a new science. New York: Viking/Penguin.

Glick, D.B. (2011) The Demographics of Online Students and Teachers in the US 2010-2011. Maplewood, $\mathrm{MN}$ : David B. Glick and Associates.

Guion, L.A., Diehl, D.C. \& McDonald, D. (2012) Triangulation: establishing the validity of qualitative studies. US Department of Agriculture, Cooperative Extension Service and University of Florida.

Healy, C.C. \& Welchert, A.J. (1990) Mentoring Relations: a definition to advance research and practice, Educational Researcher, 19(9), 17-21. http://dx.doi.org/10.3102/0013189x019009017

Hedstrom, P. \& Swedburg, R. (1998) Social Mechanisms: an analytical approach to social theory. Cambridge: Cambridge University Press. http://dx.doi.org/10.1017/СB09780511663901

Kerr, S. (2011a) Online Learning in High Schools: pedagogy, preferences, and practices of online social studies teachers, Journal of Educational Technology Systems, 39(3), 220-244.

Kerr, S. (2011b) Tips, Tools, and Techniques for Teaching in the Online High School Classroom, TechTrends, 55(1), 28-30.

Lam, Y.J. (2009) School Organizational Structures: effects on teacher and student learning, Journal of Education Administration, 43(4), 387-401. http://dx.doi.org/10.1108/09578230510605432

Means, B., Toyama, Y., Murphy, R., Bakia, M. \& Jones, K. (2009) Evaluation of Evidence-based Practices in Online Learning a Meta-analysis and Review of Online Learning Studies. Washington, DC: Office of Planning, Evaluation, and Policy Development, Center for Technology in Learning, US Department of Education.

Moreland, N., Jawaid, A. \& Dhillon, J. (2000) Quality Improvement in the TESOL Curriculum: a generic benchmarking approach, Quality Assurance in Education, 8(2), 57-62. http://dx.doi.org/10.1108/09684880010325484

Nazarko, J., Kuźmicz, K.A., SzubzdaPrutis, E. \& Urban, J. (2009) The General Concept of Benchmarking and its Application in Higher Education in Europe, Higher Education in Europe, 34(3-4), 497-510.

O'Brien, C., Hartshorne, R., Beattie, J. \& Jordan, L. (2011) A Comparison of Large Lecture, Fully Online, and Hybrid Sections of Introduction to Special Education, Rural Special Education Quarterly, 30(4), 19-31.

O'Dwyer, L.M., Carey, R. \& Kleiman, G. (2007) A Study of the Effectiveness of the Louisiana Algebra I Online Course, Journal of Research on Technology in Education, 39(3), 289-306. http://dx.doi.org/10.1080/15391523.2007.10782484

Oliver, K., Osborne, J. \& Brady, K. (2009) What are Secondary Students' Expectations for Teachers in Virtual School Environments?, Distance Education, 30(1), 23-45. http://dx.doi.org/10.1080/01587910902845923

O'Neal, K., Jones, W.P., Miller, S.P., Campbell, P. \& Pierce, T. (2007) Comparing Web-based to Traditional Instruction for Teaching Special Education Content, Teacher Education and Special Education, 30(1), 34-41. http://dx.doi.org/10.1177/088840640703000104

Peters, M.T. \& Heron, T.E. (1993) When the Best is Not Good Enough: an examination of best practice, Journal of Special Education, 26(4), 371-385. http://dx.doi.org/10.1177/002246699302600403

Rennie Center for Education Research and Policy (2010) A Focus on Achievement at Excel High School: a best practices case study, Journal of Education, 190(1/2), 3-12.

Rice, K.L. (2006) A Comprehensive Look at Distance Education in the K-12 Context, Journal of Research on Technology in Education, 38(4), 425-448. http://dx.doi.org/10.1080/15391523.2006.10782468 
Sapp, D.A. \& Simon, J. (2005) Comparing Grades in Online and Face-to-face Writing Courses: interpersonal accountability and institutional commitment, Computers and Composition, 22, 471-489. http://dx.doi.org/10.1016/j.compcom.2005.08.005

Sivin-Kachala, J. \& Bialo, E. (2009) IESD Comprehensive Technical Report Evaluation of the Social Skills of Full-Time, Online Public School Students. Memphis, TN: Center for Research in Educational Policy (CREP), Interactive Educational Systems Design (IESD).

Spencer, T.D., Detrich, R. \& Slocum, T.A. (2012) Evidence-based Practice: a framework for making effective decisions, Education and Treatment of Children, 35(2), 127-151. http://dx.doi.org/10.1353/etc.2012.0013

Suarez-Ortega, M., Ballesteros-Velaquez, B. \& Malik-Lievano, B. (2012) Educational Achievement and Effective Schools: examples of best practice, Intercultural Education, 23(12), 1-13. http://dx.doi.org/10.1080/14675986.2012.664749

Suler, J. (2004) The Online Disinhibition Effect, CyberPsychology and Behavior, 7(3), 321-325. http://dx.doi.org/10.1089/1094931041291295

Tucker, B. (2007) Laboratories of Reform: virtual high schools and innovation in public education. Washington, DC: Education Sector Reports.

US Department of Health and Human Services (2012) Identifying and Promoting Promising Practices. Washington, DC: Compassion Capital Fund.

Vesely, A. (2011) Theory and Methodology of Best Practice Research: a critical review of the current state, Central European Journal of Public Policy, 2(5), 99-117.

Watson, J., Murin, A., Vashaw, L., Gemin, B. \& Rapp, C. (2012) Keeping Pace with K-12 Online and Blended Learning: an annual review of policy and practice. Durango, CO: Evergreen Education Group.

Wilcox, K.C. \& Angelis, J.I. (2011) High School Best Practices: results from cross-case comparisons, High School Journal, 94(4), 138-153. http://dx.doi.org/10.1353/hsj.2011.0009 